\title{
Revision Total Hip Arthroplasty with Primary Stem or Full-Porous-Coated Long Stem for Aseptic Femoral Component Loosening: A Matched-Pair Study
}

\author{
Meng-Huan Tsai $\mathbb{D}^{1}$, Chun-Chieh Chen ${ }^{1-3}$, Chih-Hsiang Chang $\mathbb{D}^{1-3}$, Yuhan Chang ${ }^{1-3}$, Pang-Hsin Hsieh ${ }^{1-3}$, \\ Chih-Chien $\mathrm{Hu}$ (D) $^{1-3}$
}

'Department of Orthopedic Surgery, Chang Gung Memorial Hospital, Taoyuan, 33305, Taiwan; ${ }^{2}$ Bone and Joint Research Center, Chang Gung Memorial Hospital, Taoyuan, 33305, Taiwan; ${ }^{3}$ College of Medicine, Chang Gung University, Taoyuan, 33305, Taiwan

Correspondence: Chih-Chien Hu, Bone and Joint Research Center, Chang Gung Memorial Hospital, Kweishan, Taoyuan, 33305, Taiwan, Tel +886-3-328I200, ext. 2420, Email chihchienhu@hotmail.com

Background: Revision total hip arthroplasty (RTHA) for loosening the femoral stem is a technical challenge. Distally fixed, fullporous-coated long stems are widely accepted as the standard selection for these revisions. However, the success of primary stems in RTHA is not well known.

Methods: This study enrolled 24 patients with aseptic loosening of the femoral stem who underwent RTHA using primary stems. Another 72 patients with aseptic loosening who underwent RTHA using full-porous-coated long stems were matched in terms of operation date, proximal femoral bone stock (Paprosky classification), sex, and age. The primary and secondary outcomes of failure were the need for revision for any reason and the radiographic change in the stem respectively.

Results: In the primary stem group, one patient had a periprosthetic fracture and received a second RTHA 2 years after the previous one. The primary outcome's 5-and 10-year survival rates were both 95.8\%. For the matched comparison group, one patient had an immediate periprosthetic fracture of the femoral shaft requiring further open reduction internal fixation surgery. Another patient had a full-porous-coated long stem breakage 6 years postoperatively, which required a second RTHA. The primary outcome's 5-and 10year survival rates were $98.6 \%$ and $97.2 \%$, respectively.

Conclusion: Primary stems can achieve non-inferior clinical success compared to a full-porous-coated long stem for aseptic stem loosening RTHA in patients with adequate proximal femoral bone stock.

Keywords: revision total hip arthroplasty, aseptic loosening, primary stem, full-porous-coated long stem

\section{Introduction}

Revision total hip arthroplasty (RTHA), which represents $15 \%$ of all total hip replacements performed, is expected to increase in prevalence. ${ }^{1}$ According to Australian Orthopaedic Association National Joint Replacement Registry annual report 2021, common etiologies of RTHA procedures were prosthesis dislocation/instability (22.5\%), infection (22.3\%), fracture $(21.5 \%)$ and loosening $(21.1 \%)$. However, by type of RTHA, femoral component revision was the most common $(32.6 \%) .{ }^{2}$ The surgical goal of the femoral side is to obtain adequate primary stability with a stem that "fixes as proximal as possible and as distal as necessary". ${ }^{3}$ The appropriate prosthesis and associated equipment selection depends on the proximal femoral deficiency based on the Paprosky classification. ${ }^{4}$ In general, type 1 and 2 defects are best managed with cementless and distally fixed revision femoral components, which have been associated with excellent and predictable long-term function. ${ }^{5}$ Nonetheless, the use of revision long stems increases the complexity of the procedure and may increase the risk of intraoperative periprosthetic fracture, which reduces bone stock for future reconstructions. ${ }^{6}$ Recently, good results have been achieved with primary cementless stems in a revision setting. Cavagnaro et al reported 439 
patients (454 hips) with primary stems in revision settings for patients mostly with femoral Paprosky defect types 1 and 2 and stem-related survival rate $95.6 \% \pm 3.8$ was recorded in a systematic review. ${ }^{7}$ Currently, no study has compared the clinical results of RTHA using primary stem and full-porous-coated long stems in a single institute with the same surgical team. Therefore, this study aimed to compare the clinical results of RTHA using primary stems and full-porous-coated long stems.

\section{Materials and Methods}

\section{Patients}

A retrospective review of single institutional data using primary stem or full-porous-coated long stem in RTHA surgery was conducted. RTHA surgeries were performed by experienced surgeons from 2006 to 2018, with a minimum 3 years follow up. A total of 1965 RTHAs were performed during this period in our institute. All patients who underwent first RTHA due to aseptic loosening of the femoral stem were included. RTHA for septic loosening, hip dislocation, hip fracture, and poor proximal bone stock (Gruen zone 1 and 7 deficit) ${ }^{8}$ and Paprosky types 3 and 4 were excluded. ${ }^{4,9}$ Twenty-four patients with primary stems (VerSys ${ }^{\circledR}$ Fiber Metal Taper Hip Prosthesis, VerSys ${ }^{\circledR}$ LD/Fx Cemented Hip Prostheses, Zimmer ${ }^{\circledR}$, IN, USA; Perfecta Hip system, Wright ${ }^{\circledR}$, TN, USA; U2 Hip Stem, United ${ }^{\circledR}$, New Taipei City, Taiwan) were enrolled. Another 72 patients using cementless full-porous-coated long stems (VerSys ${ }^{\circledR}$ Beaded Full Coat Revision Hip Prosthesis, Zimmer ${ }^{\circledR}$, IN, USA; U2 revision stem, United ${ }^{\circledR}$, New Taipei City, Taiwan) were matched according to the operation date, proximal femoral bone stock (Paprosky classification), sex, and age. The patient characteristics of these two groups are shown in Table 1. No significant differences were observed in the preoperative demographic data between these two groups. The Ethics Committee of Chang Gung Memorial Hospital approved the study (IRB 202100580B0). The informed consent was obtained from all study participants and the guidelines outlined in the Declaration of Helsinki were followed.

\section{Surgical Technique}

Preoperative radiographs of patients with potential loosening were reviewed to assess the femoral bone stock according to the Paprosky classification. All surgeries were performed using a modified Hardinge (direct lateral) approach. For RTHA with primary stem, adequate debridement of the femoral canal was performed after removal of the previous loosening femoral prosthesis. Then, a cementless fixed stem was inserted after the sequential broaching technique. ${ }^{10}$ Two cases were decided intraoperatively using cemented fixation with a dedicated stem because the broach technique was inadequate to achieve stability for cementless fixation. Another nine cases with loosening cemented stem were preoperatively decided to cement a new stem on the residual cement mantle (cement-in-cement technique). ${ }^{11}$ For RTHA with a full-porous-coated long stem, after smooth removal of the femoral component, adequate femoral canal debridement and instrument reaming to ensure distal fit was achieved by measuring the adequate size and depth of the femoral canal. ${ }^{12,13}$ Using preoperative radiographic templating, the aim was to achieve a scratch fit of the femoral canal

Table I Patient Characteristics

\begin{tabular}{|l|l|l|l|}
\hline & Primary Stem & Revision Long Stem & P value \\
\hline Patient number & 24 & 72 & \\
Sex & & & I \\
$\quad$ Male & 16 & 48 & \\
Female & 8 & 24 & \\
Age & $62.3 \pm 18.1$ & $61.2 \pm 13.2$ & 0.75 \\
Body mass index & $28.0 \pm 2.0$ & $28.3 \pm 1.7$ & 0.55 \\
Paprosky type & & & 0.67 \\
I & 18 & 57 & \\
2 & 6 & 15 & 0.2 \\
Preoperative Hip Harris Score & $53.8 \pm 8.6$ & $55.6 \pm 10.3$ & \\
\hline
\end{tabular}


by engaging the distal portion of the stem tip. None of the long stem revision procedures were performed using the cementing technique.

\section{Outcome Measures}

Patients were assessed at 3,6, and 12 months and every 2 years thereafter postoperatively. Patient-reported outcome measures including Harris Hip scores (HHS) were collected preoperatively and postoperatively until latest follow up. ${ }^{14}$ Postoperative radiographs, including anteroposterior and lateral views of the hip joint, were examined for evidence of potential loosening, subsidence, fracture, or broken stem. Canal fill ratio of the stem for cementless stem was also measured, which was defined as the width of the stem divided by the width of the canal at $7 \mathrm{~cm}$ below the lesser trochanter. ${ }^{15}$ Survival rate for two kinds of outcomes were recorded and compared between 2 groups. The first was the radiographic change of femur or stem, such as loosening, subsidence, fracture, or broken stem. The second was the need for 2 nd revision for any reason. The radiographic assessments were interpreted by a senior orthopedic surgeon who had more than 10 years of interpreting hip radiography images.

\section{Statistical Analysis}

Statistical analysis was performed using SPSS version 25 (IBM, Armonk, NY), and the means, standard deviations, and ranges were used. The Pearson chi-square test was used to compare the categorical variables. An independent $t$-test was used to compare the continuous values. Kaplan-Meier survivorship analysis was used with the endpoint of radiographic change and 2nd revision with a 95\% confidence interval (CI). A Log rank test was used to compare survivorship. Statistical significance was set at $\mathrm{p}<0.05$.

\section{Result}

In the primary stem RTHA group, the average follow-up time was $7.6 \pm 3.5$ years. The HHS increased from preoperative 53.8 \pm 8.6 to $86.3 \pm 10.7(\mathrm{P}<0.001)$ at the latest follow-up, which showed significant improvement. Among the 15 cases with loosening cementless stems, 13 were revised with cementless stems, and 2 were revised with cemented stems. The canal-fill ratio for the cementless component was $84.0 \pm 5.7$ of cementless component. For 9 cases with loosening cemented stems, all were revised with dedicated cemented stems. Among primary stem RTHA group, 22 patients had femoral components that were integrated during serial follow-up without secondary subsidence, loosening, or progressive radiolucencies. One patient had asymptomatic stem subsidence 5 months postoperatively and remained stable thereafter, which exempted further management. Another patient had periprosthetic fracture caused by a traffic accident 2 years postoperatively and received a second RTHA of the femoral component (Figure 1). The 5-and 10-year survival rates for radiographic change were both $91.7 \%$. In terms of the 2 nd revision, the 5 -and 10-year survival rates were both $95.8 \%$ (Figure 2).

For the matched group, the average follow-up time was $6.8 \pm 3.3$ years. At the latest follow up, the HHS increased from preoperative $55.6 \pm 10.3$ to postoperative $86.7 \pm 9.1(\mathrm{P}<0.001)$, which showed significant improvement. The canalfill ratio was $88.9 \pm 5.9$ for the cementless full-porous-coated long stem group. Among the group, 68 patients achieved femoral component stability without secondary subsidence, loosening, or progressive radiolucencies. Two patients had asymptomatic femoral stem subsidence without further progression (both within postoperative 1 year); thus, no revision surgery was needed. One patient had intraoperative periprosthetic fracture of the femoral shaft, which required immediate open reduction internal fixation (ORIF) surgery (Figure 3). Another patient had long stem breakage due to a traffic accident that required a second RTHA in the postoperative 6 years (Figure 4). The 5- and 10-year survival rate for radiographic change of this group was $95.8 \%$ and $94.4 \%$, respectively. The 5- and 10-year survival rate for 2nd revision was $98.6 \%$ and $97.2 \%$, respectively (Figure 2). A comparison of the above data between the two groups is presented in Table 2. In terms of the comparison between two groups in survival rate for radiographic change and 2nd revision, no significant differences were revealed.

\section{Discussion}

Full-porous-coated long stem prostheses are considered to be the first choice for most femoral component revision. ${ }^{5}$ Using an extensively porous-coated cementless femoral stem for RTHA has been well established by several studies with 

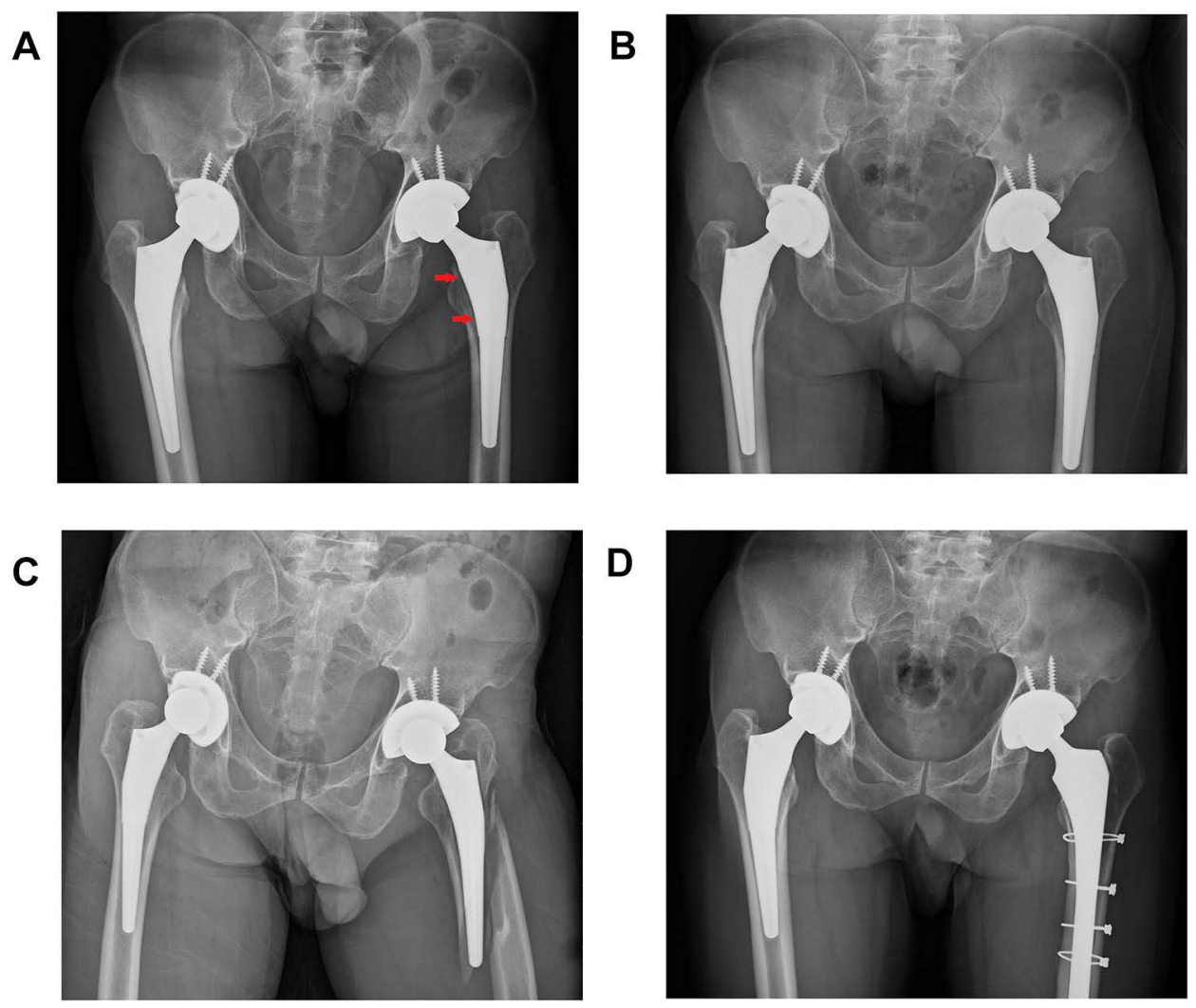

Figure I Pelvis AP radiograph of 4I-year-old patient suffered from stem loosening of primary THA, s/P periprosthetic fracture 2 years after the first RTHA with primary stem and receiving second RTHA. (A) Aseptic loosening of left femoral stem, the arrow shows the subsidence of stem and radiolucency around prosthesis before the first RTHA. (B) Immediate postoperative radiograph of the first RTHA using primary stem, which was ML taper stem from size $12.5 \mathrm{~mm}$ changed to size I5mm. (C) Periprosthetic fracture (Vancouver type B2) occurred 2 years after the first RTHA surgery. (D) Second RTHA using cementless full-porous-coated long stem and multiple wiring fixation.

excellent mid-term results. ${ }^{16-18}$ A clinical trial by Wallace et al reported $98 \%$ success in achieving stable bony ingrowth on radiographic analysis of 55 femoral stem revisions using a contemporary, cementless, and extensively porous-coated monoblock long stem with a minimum 10 years of follow-up. ${ }^{12}$ These stems are designed to bypass deficient proximal femoral bone stock and achieve stability in the isthmus. Primary stability is achieved by tight prosthetic fit and long-term stability by distal biological ingrowth. ${ }^{19}$

However, using a full-porous-coated long stem increases the complexity of the procedure, which worsens the risk of intraoperative fracture ${ }^{6}$ due to the mostly deficient bone in the proximal femur. Moreover, the distally fixed long-stem prosthesis significantly predisposes the patient to stress shielding, especially when a large-diameter femoral stem is required. This was noted in separate long-term follow-up studies published previously. ${ }^{20-22}$ Severe postoperative thigh pain of $8-9 \%$ has been reported with the use of such prostheses. ${ }^{23}$ There are also concerns, such as mismatched femoral canal bowing and high cost. Last but not the least, in patients with extensive femoral defects (Paprosky types 3 and 4), the failure rate of using these femoral stems is also reported high. ${ }^{24}$ Thus, we believe that the primary stem could play a significant role instead of full-porous-coated long stem in specific conditions, such as good proximal femoral bone stock. Cavagnaro et al concluded that the proper indication of using primary stems in RTHA is limited bone loss with a low number of previous surgeries. ${ }^{7}$ This correlates with our inclusion criteria, which are limited to Paprosky defect type 1 or 2. In addition, we excluded septic loosening of the femoral component because the gold standard for this situation requires staged surgery, which was not suitable for our data analysis. Expectedly, promising results have been achieved with primary stem in revision setting with survival rates ranging from $94.9 \%$ to $100 \%$, which mostly correlated with the reviewed projects. ${ }^{7,10,25,26}$

Subsidence of the femoral stem is frequently reported, probably due to the lack of early press-fit sufficient to withstand patient loading. ${ }^{26}$ In fact, the interpretation of secondary subsidence of the femoral component depends on the 

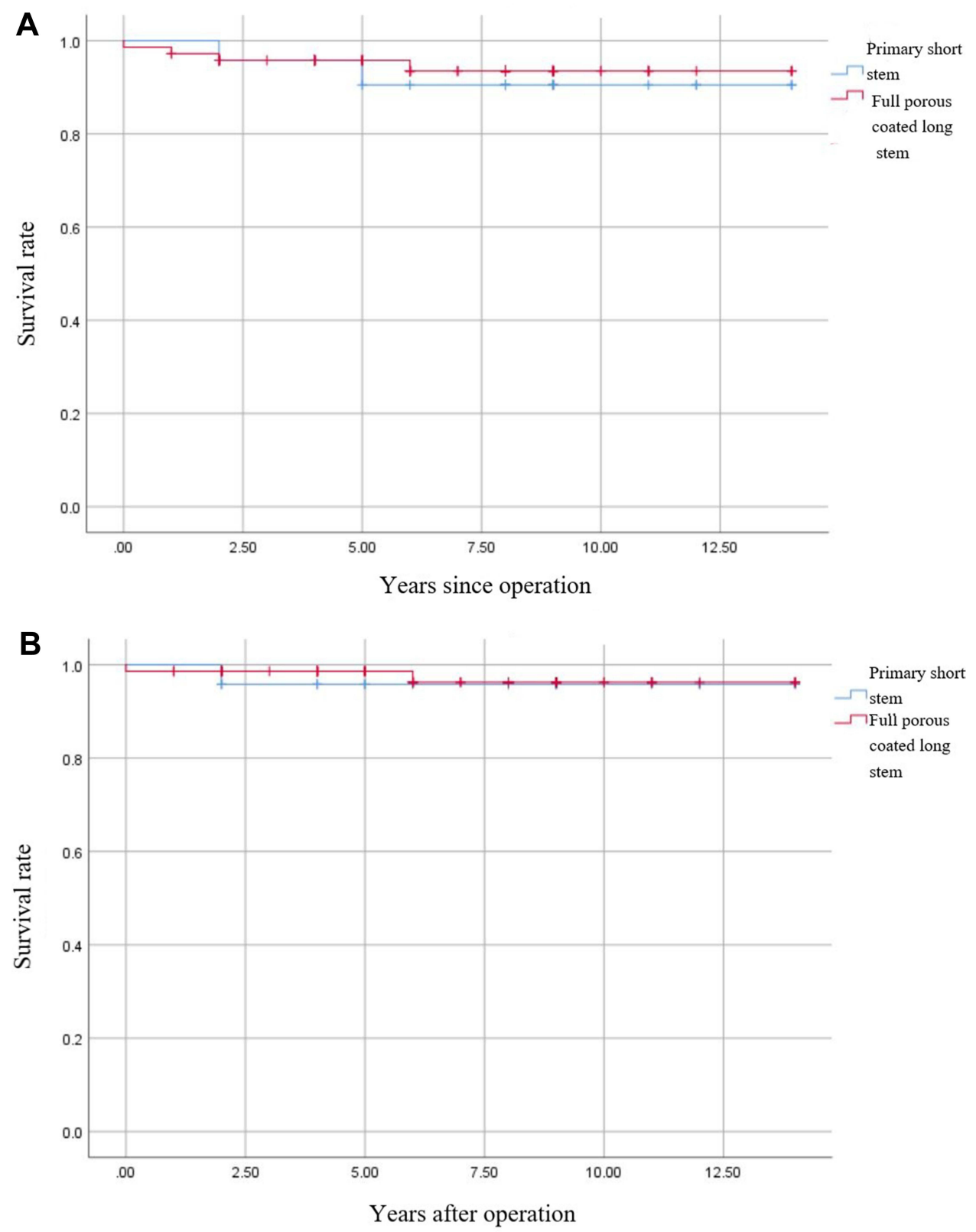

Figure 2 Kaplan-Meier survivorship curve compared between primary stem and full-porous-coated long stem groups. (A) Survivorship curve for radiographic change. (B) Survivorship curve for revision.

design of the component. With extensively porous-coated stem ("fit-and-fill" design), primary stability is obtained in the diaphyseal femoral area by close contact between the host bone and the component. With these components, secondary subsidence between 4 and $10 \mathrm{~mm}$ indicates loosening. ${ }^{22}$ With "press-fit" designs, such as primary stem, after obtaining bone-component surface contact, primary stability was obtained by a wedging effect, which is supposed to create greater stress at the bone-component interface than the destabilizing forces on the femoral stem such as rotation and subsidence strains. In our study, one subsidence occurred 5 months after the revision surgery with less than $4 \mathrm{~mm}$ in the primary stem group and two subsidence in the full-porous-coated long stem group within the first postoperative year. Nevertheless, these subsidence were clinically benign and asymptomatic, and both stem and long stems presented radiographic stability and clinical success.

A patient had intraoperative periprosthetic fracture of the femoral diaphysis, which required further ORIF surgery. The reported intraoperative fracture rate of the revision femoral component was $12 \%$, in which cementless and cemented stems 
A

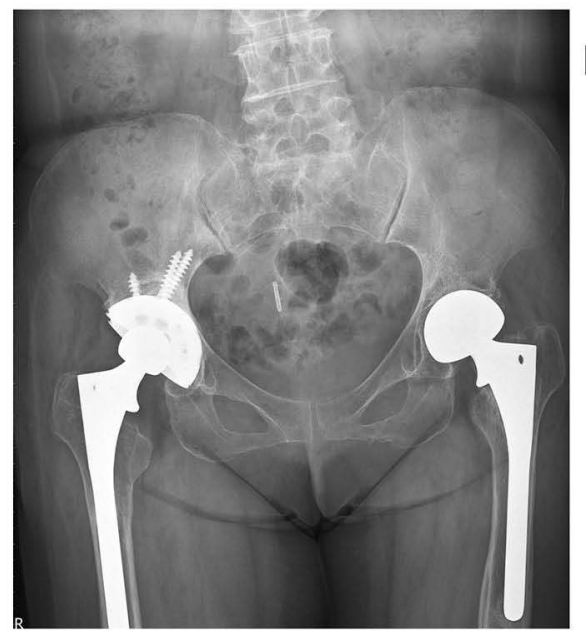

B
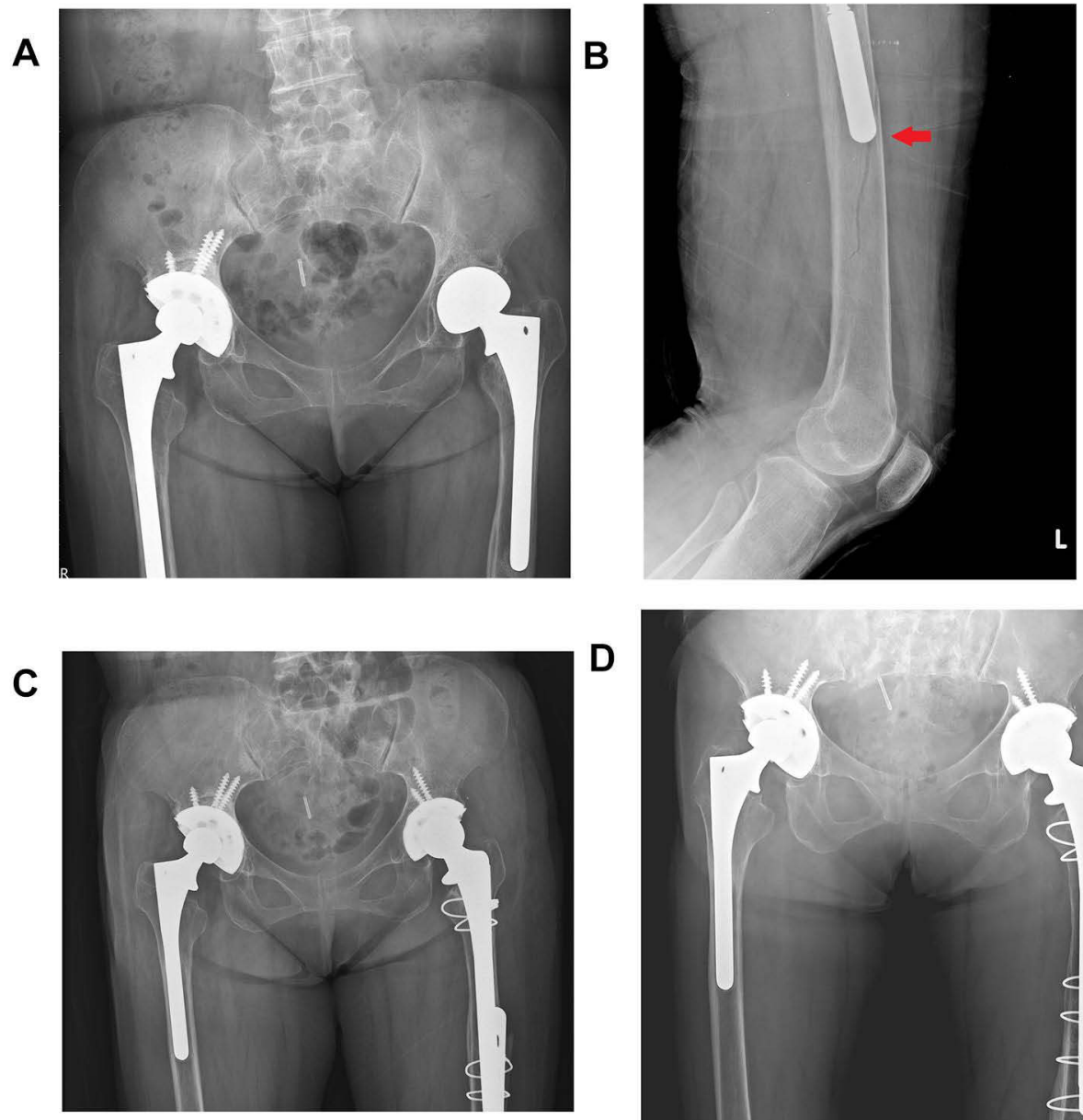

D

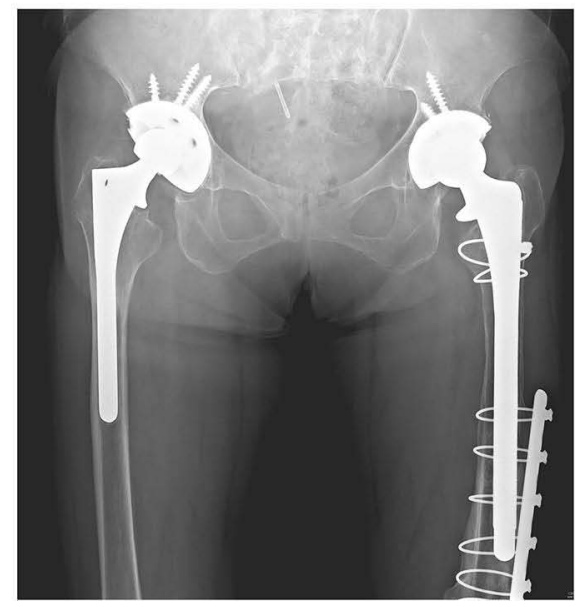

Figure 3 Pelvis and femoral radiograph of 58-year-old patient suffered from stem loosening after primary THA, intraoperative tip fracture during RTHA, and revision with long stem combined additional ORIF. (A) Aseptic loosening of left femoral stem before RTHA surgery. (B) Intraoperative radiograph revealed periprosthetic femoral shaft split fracture over stem tip (red arrow). (C) Immediate ORIF was performed combined full-porous-coated long stem RTHA. (D) 5 years postoperative radiograph revealed stable prosthesis and fracture union.

accounted for $19 \%$ and $6 \%$ of the 5417 RTHAs. ${ }^{27}$ The reported incidence of intraoperative femoral fracture varied by stem type: fully coated (20\%), proximally coated (19\%), and modular fluted tapered $(16 \%)$. ${ }^{27}$ Most fractures occurred during the insertion of the femoral component (35\%), with one-third involving the diaphysis and $26 \%$ being of the calcar crack. ${ }^{27}$ In Asian populations, especially in elderly women with stature, the extensively porous-coated long stem may not be easily applied during prosthetic insertion. The straight cylindrical extensively porous-coated long stem is too long to safely reach the femoral diaphysis without penetration of the bowing femoral canal. ${ }^{28}$ Thus, the template technique for identifying the ideal implant selection is important in patients with short stature to prevent this specific complication. Once the template is mismatched, alternative implants should be considered, such as shorter, modular fluted tapered femoral stems, or cemented ones. ${ }^{27,29}$ Moreover, fracture of the prosthetic stem body was reported by Muller. ${ }^{30}$ Most of the reported stem fractures involved cemented prostheses, probably because of the proximal cement loosening but a distally well-fixed component that allows cantilever bending forces on the stress riser. ${ }^{30}$ Fracture of cementless, full-porous-coated femoral stems are rare and causes catastrophic failure of a previously well-functioning prosthesis. We have reported a series of 17 broken stems in 251 RTHAs from 2006 to 2012 at our institute. ${ }^{31}$ To prevent this relatively rare but specific complication according to the current study, we recommended the use of primary stem either cemented or cementless for aseptic stem loosening in patients with adequate proximal femoral bone stock.

Our study has several limitations. First, it was a retrospective study with a relatively short mean follow-up period of 7 years. However, the failure of revision, such as subsidence, mostly occurred early within the first postoperative year. Although this was a retrospective study, we attempted to match the comparable cohort of 
A

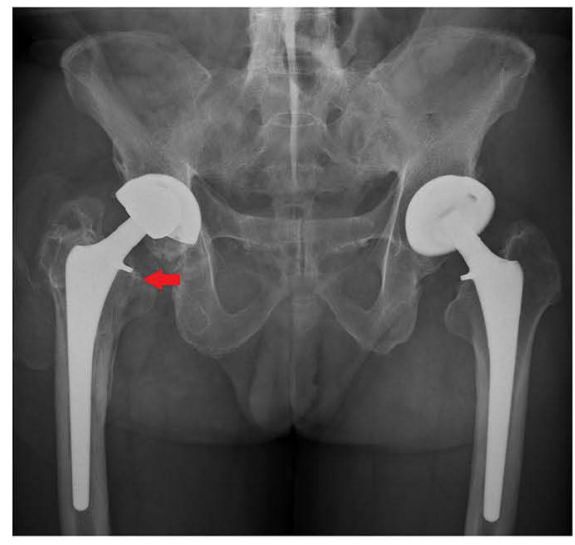

B

C

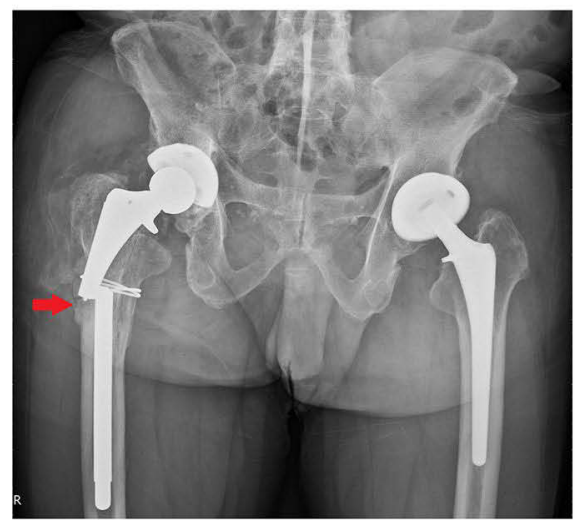

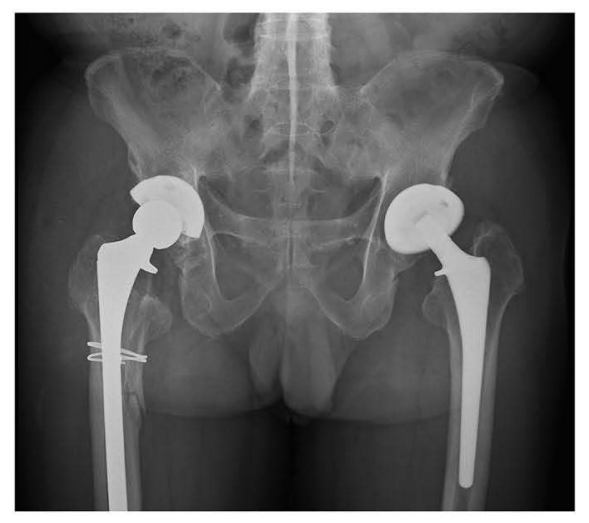

D

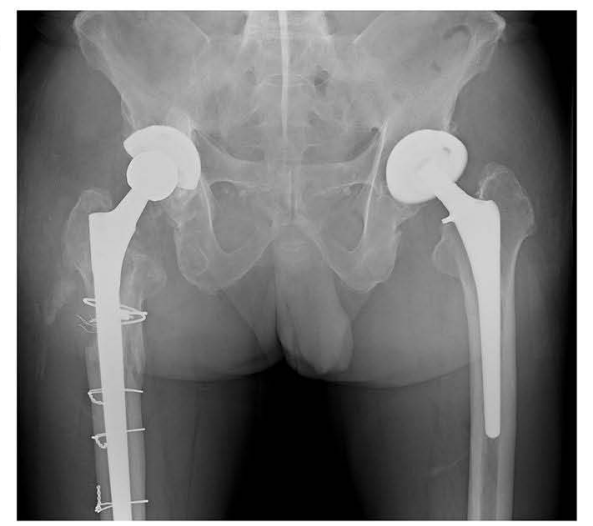

Figure 4 Radiograph of 62-year-old patient suffered from long stem breakage 6 years after the first RTHA, which was revised with a new cementless full-porous-coated long stem. (A) Aseptic loosening of right femoral stem, the arrow shows the subsidence of stem and radiolucency around prosthesis with advanced osteolysis. (B) Immediate radiograph of RTHA using full-porous-coated long stem, collar fracture was repaired with cerclage wire. (C) Long stem breakage (red arrow) occurred 6 years after revision surgery. (D) Second RTHA using cementless full-porous-coated long stem with multiple wiring ORIF.

primary stem and full-porous-coated long stem according to implant selection, bone stock classification, sex, and age demographics to identify potential differences. Most importantly, the results of the current study are specific but comparable to those in the literature on femoral revision of RTHAs. ${ }^{7,10,25,26}$ Second, technical details associated with bone grafting or cementing technique varied because the device's characteristics were the most difficult to present. However, the single institute and same surgical team analysis realized the adequate technical and individual control of surgeon bias, which provided reliable information for clinical application. Third, the composing of 11 cemented and 13 cementless stem in revision setting of primary stem group might affect the outcome and further study is needed to address this issue. Last but the least, the number of cases in this series was relatively small (24 +72 cases), which showed that the indications for adequate proximal femoral bone stock femoral component revision were limited in case number. However, because of the restricted indication of inclusion, this homogeneous matchedpaired study provided sufficient reference value for orthopedic surgeons in terms of femoral component RTHA. Nonetheless, we advise a prospective standardization of the methodological analysis to compare the available data and achieve definitive results.

\section{Conclusion}

In our study, with adequate patient selection and delicate preoperative femoral bone stock evaluation, we affirm that the primary stem in femoral revision RTHA represents an available and feasible option because it can achieve non-inferior clinical success compared to a full-porous-coated long stem. 
Table 2 Clinical Outcomes of Primary Stem and Revision Long Stem

\begin{tabular}{|c|c|c|c|}
\hline & Primary Stem & Revision Long Stem & P-value \\
\hline Average follow up time (years) & $7.6 \pm 3.5$ & $6.8 \pm 3.3$ & 0.32 \\
\hline Postoperative Hip Harris Score at latest follow up & $86.3 \pm 10.7$ & $86.7 \pm 9.1$ & 0.72 \\
\hline Cement Condition & & & $<0.001$ \\
\hline Cemented $\rightarrow$ cemented & 9 & 0 & \\
\hline Cemented $\rightarrow$ cementless & 0 & 20 & \\
\hline Cementless $\rightarrow$ cementless & 13 & 52 & \\
\hline Cementless $\rightarrow$ cemented & 2 & 0 & \\
\hline \multicolumn{4}{|l|}{ Radiographic } \\
\hline Canal fill ratio & $84.0 \pm 5.7$ & $88.9 \pm 5.9$ & 0.006 \\
\hline Radiographic change & & & 0.69 \\
\hline Stem subsidence & I & 2 & \\
\hline Periprosthetic fracture & 1 & I & \\
\hline Stem breakage & 0 & I & \\
\hline 5 -year survival rate & $91.7 \%$ & $95.8 \%$ & \\
\hline 10-year survival rate & $91.7 \%$ & $94.4 \%$ & \\
\hline 2nd Revision & & & 0.78 \\
\hline Periprosthetic fracture & 1 & I & \\
\hline Stem breakage & 0 & I & \\
\hline 5-year survival rate & $95.8 \%$ & $98.6 \%$ & \\
\hline I0-year survival rate & $95.8 \%$ & $97.2 \%$ & \\
\hline
\end{tabular}

\section{Acknowledgment}

There are no contributors.

\section{Author Contributions}

All authors contributed to data analysis, drafting or revising the article, have agreed on the journal to which the article will be submitted, gave final approval of the version to be published, and agree to be accountable for all aspects of the work.

\section{Disclosure}

The authors report no conflicts of interest in this work.

\section{References}

1. Haynes JA, Stambough JB, Sassoon AA, Johnson SR, Clohisy JC, Nunley RM. Contemporary surgical indications and referral trends in revision total hip arthroplasty: a 10-year review. J Arthroplasty. 2016;31(3):622-625. doi:10.1016/j.arth.2015.09.026

2. Graves S; Australian Orthopaedic Association National Joint Replacement Registry (AOANJRR). Hip, knee \& shoulder arthroplasty: 2021 Annual Report. Adelaide: AOA; 2021:1-432.

3. Böhm P, Bischel O. The use of tapered stems for femoral revision surgery. Clin Orthop Relat Res. 2004;420:148-159. doi:10.1097/00003086200403000-00021

4. Della Valle CJ, Paprosky WG. Classification and an algorithmic approach to the reconstruction of femoral deficiency in revision total hip arthroplasty. J Bone Joint Surg Am. 2003;85-A(Suppl 4):1-6. doi:10.2106/00004623-200300004-00001

5. Brown JM, Mistry JB, Cherian JJ, et al. Femoral component revision of total hip arthroplasty. Orthopedics. 2016;39(6):e1129-e1139. doi:10.3928/ 01477447-20160819-06

6. Davidson D, Pike J, Garbuz D, Duncan CP, Masri BA. Intraoperative periprosthetic fractures during total hip arthroplasty: evaluation and management. J Bone Joint Surg Am. 2008;90(9):2000-2012. doi:10.2106/JBJS.H.00331

7. Cavagnaro L, Formica M, Basso M, Zanirato A, Divano S, Felli L. Femoral revision with primary cementless stems: a systematic review of the literature. Musculoskeletal Surg. 2018;102(1):1-9.

8. Gruen TA, McNeice GM, Amstutz HC. "Modes of failure" of cemented stem-type femoral components: a radiographic analysis of loosening. Clin Orthop Relat Res. 1979;141:17-27.

9. Paprosky WG, Aribindi R. Hip replacement: treatment of femoral bone loss using distal bypass fixation. Instr Course Lect. 2000;49:119-130. 
10. Kelly SJ, Incavo SJ, Beynnon B. The use of a hydroxyapatite-coated primary stem in revision total hip arthroplasty. $J$ Arthroplasty. $2006 ; 21$ (1):64-71. doi:10.1016/j.arth.2004.11.013

11. Eftekhar NS. Principles of Total Hip Arthroplasty. Missouri: CV Mosby Company; 1978.

12. Wallace CN, Chang JS, Kayani B, Moriarty PD, Tahmassebi JE, Haddad FS. Long-term results of revision total hip arthroplasty using a modern extensively porous-coated femoral stem. J Arthroplasty. 2020;35(12):3697-3702. doi:10.1016/j.arth.2020.06.052

13. Schuh A, Werber S, Holzwarth U, Zeiler G. Cementless modular hip revision arthroplasty using the MRP Titan Revision Stem: outcome of 79 hips after an average of 4 years' follow-up. Arch Orthop Trauma Surg. 2004;124(5):306-309. doi:10.1007/s00402-004-0656-7

14. Harris WH. Traumatic arthritis of the hip after dislocation and acetabular fractures: treatment by mold arthroplasty. An end-result study using a new method of result evaluation. J Bone Joint Surg Am. 1969;51(4):737-755. doi:10.2106/00004623-196951040-00012

15. Ishii S, Homma Y, Baba T, Ozaki Y, Matsumoto M, Kaneko K. Does the canal fill ratio and femoral morphology of Asian females influence early radiographic outcomes of total hip arthroplasty with an uncemented proximally coated, tapered-wedge stem? J Arthroplasty. 2016;31 (7):1524-1528. doi:10.1016/j.arth.2016.01.016

16. Hamilton WG, Cashen DV, Ho H, Hopper RH Jr, Engh CA. Extensively porous-coated stems for femoral revision: a choice for all seasons. J Arthroplasty. 2007;22(4):106-110. doi:10.1016/j.arth.2007.01.002

17. Hamilton WG, McAuley JP, Tabaraee E, Engh CA Sr. The outcome of rerevision of an extensively porous-coated stem with another extensively porous-coated stem. J Arthroplasty. 2008;23(2):170-174. doi:10.1016/j.arth.2007.03.038

18. Engh CA Jr, Hopper RH Jr, Engh CA Sr. Distal ingrowth components. Clin OrthopRelat Res. 2004;420:135-141. doi:10.1097/00003086200403000-00019

19. Halliday BR, English HW, Timperley AJ, Gie GA, Ling RS. Femoral impaction grafting with cement in revision total hip replacement: evolution of the technique and results. J Bone Joint Surg Br. 2003;85(6):809-817. doi:10.1302/0301-620X.85B6.13806

20. Moreland JR, Moreno MA. Cementless femoral revision arthroplasty of the hip: minimum 5 years follow up. Clin Orthop Relat Res. 2001;393:194-201. doi:10.1097/00003086-200112000-00022

21. Engh CA Jr, McAuley JP, Sychterz CJ, Sacco ME, Engh CA Sr. The accuracy and reproducibility of radiographic assessment of stress-shielding: a postmortem analysis. J Bone Joint Surg Am. 2000;82(10):1414-1420. doi:10.2106/00004623-200010000-00007

22. Paprosky WG, Greidanus NV, Antoniou J. Minimum 10-year-results of extensively porous-coated stems in revision hip arthroplasty. Clin Orthop Relat Res. 1999;369:230-240. doi:10.1097/00003086-199912000-00024

23. Richards CJ, Duncan CP, Masri BA, Garbuz DS. Femoral revision hip arthroplasty: a comparison of two stem designs. Clin Orthop Relat Res. 2010;468(2):491-496. doi:10.1007/s11999-009-1145-7

24. Sporer SM, Paprosky WG. Revision total hip arthroplasty: the limits of fully coated stems. Clin Orthop Relat Res. 2003;417:203-209.

25. Thorey F, Lerch M, Kiel H, von Lewinski G, Stukenborg-Colsman C, Windhagen H. Revision total hip arthroplasty with an uncemented primary stem in 79 patients. Arch Orthop Trauma Surg. 2008;128(7):673-678. doi:10.1007/s00402-007-0462-0

26. Tetreault MW, Shukla SK, Yi PH, Sporer SM, Della Valle CJ. Are short fully coated stems adequate for "simple" femoral revisions? Clin Orthop Relat Res. 2014;472(2):577-583. doi:10.1007/s11999-013-3167-4

27. Abdel MP, Houdek MT, Watts CD, Lewallen DG, Berry DJ. Epidemiology of periprosthetic femoral fractures in 5417 revision total hip arthroplasties: a 40-year experience. Bone Joint J. 2016;98(4):468-474. doi:10.1302/0301-620X.98B4.37203

28. Lewallen DG, Berry DJ. Periprosthetic fractures of the femur: principles of prevention and management. Instr Course Lect. 1998;47:243-249.

29. Bissias C, Kaspiris A, Kalogeropoulos A, et al. Factors affecting the incidence of postoperative periprosthetic fractures following primary and revision hip arthroplasty: a systematic review and meta-analysis. J Orthop Surg Res. 2021;16(1):15. doi:10.1186/s13018-020-02152-0

30. Müller ME. Total hip prostheses. Clin Orthop Relat Res. 1970;72:46-48.

31. Chang CH, Lin PC, Shih CM, Chen CC, Hsieh PH, Shih HN. Fracture of cobalt chrome, fully-coat beaded femoral revision long stem, a clinical outcomes study. Biomed J. 2018;41(1):46-51. doi:10.1016/j.bj.2018.02.001

Orthopedic Research and Reviews

Dovepress

\section{Publish your work in this journal}

Orthopedic Research and Reviews is an international, peer-reviewed, open access journal that focusing on the patho-physiology of the musculoskeletal system, trauma, surgery and other corrective interventions to restore mobility and function. Advances in new technologies, materials, techniques and pharmacological agents are particularly welcome. The manuscript management system is completely online and includes a very quick and fair peer-review system, which is all easy to use. Visit http://www.dovepress.com/testimonials.php to read real quotes from published authors.

Submit your manuscript here: https://www.dovepress.com/orthopedic-research-and-reviews-journal 